\title{
UN ASPECTO CONSTRUCTIVO DE LAS BÓVEDAS EN AL-ANDALUS ${ }^{1}$
}

\author{
Antonio ALMAGRo \\ CSIC. Granada
}

Este estudio tiene por objeto analizar un aspecto constructivo que subyace en una parte importante de las bóvedas andalusíes. La bóveda, como tipo estructural destinado a transmitir horizontalmente cargas verticales, construido con materiales que trabajan fundamentalmente a compresión, suele presentar en su ejecución su mayor dificultad, pues durante ciertas fases del proceso constructivo puede no ser capaz de sostenerse sin la ayuda de medios auxiliares provisionales. Como ya indicara Eduardo Torroja (1960:287), el proceso constructivo condiciona en gran medida las soluciones estructurales. $\mathrm{Y}$ en el proceso constructivo, los medios auxiliares y el proceso de ejecución de muchas obras de arquitectura e ingeniería suponen por sí, en ocasiones, mayores costes e incluso mayores logros técnicos que la propia obra permanente. Estos medios auxiliares, por su naturaleza de obras provisionales y efímeras, tienden a ser realizados con materiales que permitan su recuperación y por tanto suelen ejecutarse preponderantemente con madera. De entre los medios auxiliares necesarios para la construcción de una bóveda los más importantes son las cimbras. Las cimbras son estructuras que sirven tanto para definir la forma de la bóveda y son por ello auténticos moldes, como para soportar las piezas que la integrarán en tanto éstas no son capaces de funcionar como tal bóveda.

Pese a su mayor coste de ejecución, la bóveda suele tener mayor durabilidad y resistencia y no se ve amenazada por los peligros que acechan a la madera: ataques xilófagos, fuego, etc. Las obras abovedadas tienen siempre mayor robustez, pues la transmisión de las cargas hasta los apoyos sin que intervengan esfuerzos de tracción obliga a establecer sistemas de contrarresto para los empujes que se generan, originando construcciones con grandes masas de fábrica.

En numerosas áreas geográficas, en las que la madera escasea, la bóveda ha sido una solución tradicional para el cubrimiento de los espacios arquitectónicos. Pero en este punto surge una cierta contradicción, ya que si la bóveda evi-

\footnotetext{
${ }^{1}$ El presente trabajo recoge la exposición realizada por el autor en la Mesa Redonda sobre «Fábricas y Bóvedas Andalusíes en el contexto del medievo español», celebrada durante el III Congreso de Historia de la Construcción en Sevilla el 28 de octubre de 2000.
} 
ta el uso de la madera para realizar los elementos horizontales de una construcción, en su ejecución normal se precisa de cimbras cuya construcción requiere de abundante madera. Es cierto que la madera de las cimbras es recuperable en una elevada proporción y que, además, la piezas que se requieren para construir estos medios auxiliares suele ser de dimensiones mucho menores de las que serían necesarias para hacer una cubierta lígnea diáfana. Sin embargo, hay áreas geográficas en las que incluso conseguir esta madera resulta un grave inconveniente. Y precisamente en estas zonas se puede observar que se han desarrollado técnicas constructivas acordes con el problema, que obvian casi por completo el uso de la madera. En toda la zona del Oriente Próximo, desde el Mediterráneo hasta el Índico, incluyendo parte del norte de África, se dan condiciones de escasez de madera para construcción. Tradicionalmente se han utilizado dos soluciones estructurales: grandes dinteles de piedra o bóvedas de cantería. En estas construcciones no cabe duda de que se usaba madera para los medios auxiliares en ambos casos y en ocasiones se traía madera desde largas distancias para construir determinadas estructuras de cubrimiento. Pero en zonas en las que la madera escasea aún más y en las que no hay piedra de calidad, como en amplias áreas de Mesopotamia y Persia, se desarrollaron técnicas para construir bóvedas sin recurrir al uso de la cantería ni de la madera.

Estas técnicas están ligadas al aprovechamiento de las propiedades de un material de construcción, el yeso, que permite operaciones imposibles con otros conglomerantes (Almagro, 1986). Si debiéramos resumir estas propiedades diríamos que es un producto cuya materia prima es abundante en muchas zonas geográficas, de fácil extracción, bajo coste de fabricación que no requiere de especiales requisitos técnicos, alta viscosidad y adherencia tras el amasado, rápido fraguado, moderada resistencia a compresión, nada despreciable a tracción y alta elasticidad. Sus mayores inconvenientes se encuentran en su comportamiento frente al agua por su solubilidad e higroscopicidad. Sin embargo, su comportamiento no presenta especiales problemas en zonas áridas o de lluvia moderada, pudiendo en tales circunstancias usarse a la intemperie. Su alta viscosidad y adherencia permiten construir adhiriendo mampuestos de pequeño tamaño, incluso desafiando el efecto de la gravedad, y su rápido fraguado ayuda a procesos de ejecución rápidos.

El Islam, extendido inicialmente por estas áreas en las que escasea la madera, ha servido de propagador de técnicas o «culturas constructivas» que evitan su uso tanto en la construcción como en los medios auxiliares. Resulta incluso destacable cómo determinadas «culturas constructivas» se han difundido en áreas alejadas de sus zonas de origen y en lugares en los que no existen los condicionantes que las generaron, merced sin duda a las propias ventajas que sus 
técnicas aportan. Parece en todo caso bastante claro que nuevas situaciones políticas y culturales facilitan la difusión de tradiciones y técnicas constructivas desconocidas con anterioridad en zonas distantes.

Desgraciadamente no abunda la información sobre los aspectos constructivos en los estudios de Historia de la Arquitectura, ya que en general han sido ignorados o escasamente atendidos por quienes se han dedicado a esta disciplina. Pero pensamos que hay datos suficientes para considerar que el uso del yeso como material constructivo estructural se implantó en al-Andalus de la mano de los musulmanes, sin duda transmitido desde Mesopotamia y Persia.

\section{USO DE ELEMENTOS AUXILIARES PREFABRICADOS DE YESO}

Como muestra de la temprana difusión de este tipo de técnicas por el mundo musulmán podemos citar el uso de piezas prefabricadas de yeso que sirven de medios auxiliares durante el proceso constructivo y que permanecen finalmente integradas en la propia fábrica. En el alcázar omeya de Amman encontramos el recurso de utilizar determinados elementos prefabricados de yeso para permitir una construcción más rápida y con menos medios auxiliares. Hay que advertir que estas técnicas se aplicaron en un medio donde predominaba la tradición constructiva helenística y romana, con fábricas de buena cantería o de mampostería sentada con mortero de cal, por lo que la introducción de estas nuevas técnicas fue sin duda consecuencia de la movilidad de operarios que se produjo con la formación del imperio omeya y los grandes programas constructivos acometidos durante el gobierno de esta dinastía (Creswell 1969:143,151).

Entre los restos de las arquerías del llamado edificio F (Almagro et alii, 2000:105-123), situado dentro del palacio, caídas sin duda por efecto del terremoto que destruyó este complejo, se ha podido individualizar con claridad la utilización de dos elementos prefabricados distintos. Se trata, en primer lugar, de unas placas cuadradas de $80 \mathrm{~cm}$ de lado y 4 o $5 \mathrm{~cm}$ de espesor, que se usaban a modo de capitel sobre las columnas cilíndricas. Servían para realizar la transición de la sección circular de la columna a la sección cuadrada de las impostas de los arcos (Fig. 1). Como el material utilizado es siempre piedra irregular, estas piezas servían no sólo para dar un perfil regular a las aristas, sino como elementos de soporte auxiliar, pero perdidos luego en la propia obra, sobre los que apoyar la primeras piedras de los arcos. Las placas presentan una cara bien alisada, mientras la otra aparece rugosa. El análisis de distintas piezas similares aparecidas demuestra que se prefabricaban, seguramente con un 
sencillo molde de madera, en el suelo sobre un simple lecho de arena. La cara superior, que luego era colocada boca abajo para quedar parcialmente aparente, se alisaba con cuidado, probablemente con una llana o instrumento similar. La cara inferior, sobre la que luego se iniciaba la construcción de los arcos, quedaba rugosa con la forma del lecho, facilitando una mejor adherencia del yeso y la mampostería. Para permitir una cierta continuidad de las fábricas e impedir que estas placas supusieran un punto de deslizamiento en la estructura, en el centro de las mismas se dejaba un orificio de unos $20 \mathrm{~cm}$ de diámetro, de forma muy irregular y abierto cuando el yeso aún no había fraguado. El hecho de que los orificios tengan forma de tronco de cono invertido, aunque muy irregular, demuestra que éste se hacía con el yeso sin fraguar y en la misma posición en la que eran fabricadas las placas.

Las otras piezas prefabricadas son unas piezas planas de directriz curva utilizadas para definir las aristas del intradós de los arcos (Fig. 1). Estas piezas, cuya sustentación en obra se haría mediante soportes muy ligeros hechos con maderas y palos de escasa entidad, debían cumplir varias funciones. En primer lugar definían la forma de los arcos no sólo durante la ejecución de la obra, sino que como elementos perdidos constituían las aristas del intradós. Además servían a su vez y en cierta forma de cimbra para la mampostería que formaba los arcos, que al estar recibida con yeso se adhería con facilidad a estas piezas, pudiéndose de este modo construir toda la estructura con muy escasos medios auxiliares. Cuando toda la masa muraria se enlucía con yeso, estas piezas, al igual que las que hacían de ábacos, quedaban totalmente ocultas.

La utilización de este tipo de elementos prefabricados de yeso con función de cimbras, ya sea como elementos perdidos dentro de la fábrica o como piezas independientes recuperables o desechables, está documentada en Irán todavía en tiempos recientes. En unos apuntes del profesor G. Zander, gran conocedor de la arquitectura persa, distribuidos en el curso del ICCROM de Roma en 1973, se recogían este tipo de técnicas para la construcción de cúpulas de mampostería y yeso mediante cimbras ligeras hechas asimismo con placas de yeso. Por otro lado, también hemos podido comprobar el empleo de piezas parecidas en los arcos diafragma de una construcción coetánea al alcázar de Amman en Jordania: el pequeño castillo del desierto conocido como Qasr alJarāna (Urice, 1987). Este edificio, asimismo de clarísima influencia sasánida y construido con mampostería recibida con mortero de yeso (Almagro, 1983a:184), presenta una serie de salones cubiertos con arcos transversales sobre los que apoyan bóvedas de perfil muy rebajado. En estos arcos transversales, cuyo aparejo es muy peculiar, adaptado sin duda para su construcción sin cimbra, se aprecia el uso de placas prefabricadas para formar las partes centra- 
les de los mismos. También aparece esta técnica utilizada en Ujayḍir, en Iraq, (Cresswell, 1940:61). En la figura 42 aparece descrita claramente esta técnica, en ese caso para arcos de ladrillo, que sin duda procede también de Mesopotamia y Persia.

Estos detalles constructivos, que quizás puedan tener un carácter anecdótico, resultan no obstante muy ilustrativos de lo expresado anteriormente, pues se trata sin duda de habilidades constructivas que sólo quienes las han practicado habitualmente serían capaces de realizar con soltura y de forma sistemática. Resulta en todo caso paradójico que no se utilicen en el palacio de Amman técnicas que permiten construir bóvedas de ladrillo sin cimbra, que sí se utilizaron en edificios cercanos coetáneos. Las bóvedas que hemos podido conocer o conjeturar sobre su disposición en el alcázar de Amman, sabemos que estaban construidas con piedras con una labra incipiente y con forma de dovelas y por tanto sostenidas por cimbras durante el proceso constructivo. El ladrillo, que hubiera hecho factible el construir sin dichos elementos auxiliares, sólo aparece utilizado en el hipocausto del baño y posiblemente en los antepechos de las terrazas.

No todas estas técnicas se difundieron por igual en todo el mundo musulmán. El uso del yeso sí se generalizó en el norte de África y en al-Andalus. Las técnicas de construcción de bóvedas de ladrillo sin cimbras llegaron también a la Península y están bien documentadas en época nazarí (Almagro, 1991a) y también con anterioridad (Hernández, 1975). Disposiciones como el arranque de arcos y bóvedas en un ligero saliente de escasos centímetros que caracteriza las construcciones omeyas y anteriores como un intento de reducir la luz del vano las tenemos en época emiral (Almagro, 1983b:98) y se mantienen como recurso característico en todos los períodos del dominio musulmán de la Península Ibérica. El uso de piezas prefabricadas de yeso es bien conocida en las organizaciones decorativas. Sin embargo, está todavía por hacer un estudio en profundidad sobre la disposición y el proceso constructivo de la bóvedas de mocárabes hechas de yeso. A título de hipótesis, no resulta aventurado suponer que estas sorprendentes estructuras se realizaran a base de piezas prefabricadas que eran luego agrupadas en su posición definitiva con el auxilio de ligeras cimbras o simples apuntalamientos, siguiendo el mismo proceso usado con los mocárabes de madera. No sabemos nada del posible uso de piezas de yeso para formar cimbras o como elementos auxiliares perdidos en la fábrica como los descritos de Amman. Seguramente, un análisis más cuidadoso de las estructuras y sus procesos constructivos puede todavía en un futuro aportarnos nuevos datos al respecto.

Aunque más adelante volveremos sobre el tema, podemos apuntar la hipótesis de que alguna bóveda de arcos entrecruzados se haya también servido de 
este procedimiento de construcción con piezas prefabricadas. Me estoy refiriendo en concreto a la bóveda conservada en una de las casas del patio de Banderas del Alcázar de Sevilla, la llamada Toro-Buiza (Manzano, 1995:346) muchas veces citada y prácticamente sin estudiar hasta ahora. Manzano afirma que está construida con arcos de ladrillo a panderete, aunque su complejidad permite hacer pensar que dichos arcos pudieron ser prefabricados sobre una superficie horizontal antes de ser colocados en su posición vertical.

\section{BÓVEDAS DE LADRILLOS PUESTOS A BOFETÓN, CONSTRUIDAS SIN CIMBRA}

Una técnica muy singular, sin duda de origen oriental y que llegó hasta alAndalus, es la que permite construir bóvedas de ladrillos sin cimbra ni elemento auxiliar alguno. La técnica consiste en roscar las bóvedas usando ladrillo con las piezas sentadas con yeso y a bofetón sobre la rosca anterior iniciando el proceso a partir de uno de los muros de los testeros. Esta técnica es de origen oriental y muy antigua. Se utilizó ya en el Egipto faraónico y profusamente en la Persia sasánida (Creswell, 1969:544). Desde allí se difundió por todo el mundo islámico. Espléndidos ejemplos los tenemos en los palacios omeyas de Mušattā y Qașr al-Ṭūba (Fig. 2) (Creswell, 1969:589, fig. 648, pl. 118 b-c, 138). En la España musulmana hay un ejemplo del siglo x ciertamente particular, como es la bóveda de la escalera helicoidal del alminar de S. Juan de los Caballeros de Córdoba (Hernández Giménez, 1975:143-4, L. XXVII) ${ }^{2}$. Otro ejemplo posterior es la bóveda que cubre el pasadizo de acceso al aljibe de la casa de las Veletas, hoy Museo Provincial de Cáceres. Torres Balbás la considera del siglo XII (Torres Balbás, 1948: 471, lám. 12).

Pero ejemplos más claros los podemos encontrar en construcciones de época nazarí. Así, en la Alhambra hay una bóveda de este tipo en la llamada sala de las Ninfas, que constituye el sótano que soporta la sala de la Barca del palacio de Comares, obra casi con seguridad de Yūsuf I. También en el estrecho corredor que rodea por el oeste el aljibe existente en el lado sur del patio de los Leones existe una bóveda de cuarto de cañon realizada del mismo modo. Aunque el aljibe es anterior, la bóveda que enlaza con fábricas de época de Muhammad V hay que atribuirla a este período.

En una torre situada en la vega de Granada, junto al pueblo de Romilla (Almagro, 1991a), merecen nuestra atención las bóvedas del aljibe y de la plan-

\footnotetext{
${ }^{2}$ Félix Hernández cita un precedente preislámico en una bóveda de la iglesia visigoda de S. Fructuoso de Montellios, que pudo tener influencia bizantina.
} 
ta baja por responder a similar técnica constructiva. Merced al estado de semirruina en que se encuentran las bóvedas, se puede analizar con facilidad el modo en que fueron ejecutadas, resultando este ejemplo enormemente ilustrativo (Fig. 3). Estas bóvedas están construidas claramente sin necesidad de cimbra, colocando las roscas de ladrillo a bofetón, cogidas con yeso sobre la rosca anterior. La primera se pegó a uno de los testeros, que debió de levantarse previamente hasta la altura de la clave. Ello hace que las hiladas de ladrillo tengan dirección perpendicular al eje de la bóveda, en lugar de seguir su misma dirección, como es habitual. Esta forma constructiva exige el empleo de yeso como material de agarre, ya que solo así puede conseguirse que los ladrillos se sustenten antes de cerrarse la rosca merced a la fuerte adherencia inicial de este conglomerante.

Del análisis de lo ahora visible cabe deducir que el proceso constructivo de estas bóvedas fue el siguiente (Fig. 4). Rellenos y desencofrados los cajones de tapial que debían de acompañar el arranque de la bóveda, se cajeó en ellos el apoyo de ésta, iniciándose con hiladas normales a lo largo hasta la altura en que los ladrillos aún pueden sustentarse sin escurrirse pese a carecer de cimbra. La construcción previa de estos cajones de tapial aseguraba el contrarresto de los empujes de la rosca de ladrillo. Al mismo tiempo, se levantaba en el testero una pared de ladrillo hasta la altura de la clave de la bóveda. Contra esta pared se pegaba la primera rosca de ladrillo de la bóveda a bofetón y perpendicular por tanto al eje. Sobre cada rosca levantada se iba pegando la siguiente, y así hasta concluir la bóveda sin necesidad de cimbra. Concluida la fábrica de ladrillo, los riñones o senos de la bóveda se rellenaban simultáneamente con los cajones de los muros exteriores, formando así una masa monolítica que ha permitido que se sustente a pesar de haber desaparecido en muchas zonas la bóveda de ladrillo.

Resulta obligado plantearse cómo después de utilizar una técnica que evita el empleo de cimbras se haya cambiado de forma constructiva en los dos pisos superiores, en que se dispusieron bóvedas esquifadas. Sin embargo, si analizamos con detenimiento la forma y comportamiento de esas bóvedas no es aventurado suponer que éstas pudieron también ser construidas sin ayuda de cimbras o en todo caso con estructuras de poca entidad. En Irán existe aún hoy día una larga tradición de construir cúpulas y bóvedas sin tener que acudir a la ayuda de cimbras de madera, material escaso en la región. Sabido es que si una cúpula, y la bóveda esquifada se asemeja bastante a ella en su comportamiento estructural, se va construyendo por hiladas completas y cerradas, éstas pueden trabajar como anillos a compresión y sustentarse por sí solos con tal de que las piezas de cada hilada puedan sostenerse hasta que la hilada se cierre. Esto últi- 
mo no resulta difícil de lograr si los ladrillos se asientan con yeso. Seguramente sólo se emplearía un ligero costillaje que serviría además de directriz de la bóveda y evitaría el peligro de vuelco, sobre todo de los paños largos de la bóveda alta. De forma semejante, aunque sin emplear yeso pero con un perfil más apuntado, se construyeron en el Renacimiento distintas cúpulas, como la de Brunelleschi para Santa María del Fiore, y todavía hasta época reciente se construían en muchos sitios de España bóvedas esquifadas y baídas, tanto tabicadas como roscadas de ladrillo sin utilizar cimbras o con la ayuda de simples costillajes. El que la bóveda sea roscada con $1 / 2$ pie o un 1 pie de espesor no supone en principio un problema insalvable para construirlas de esta forma (Sánchez, 2000). Las bóvedas esquifadas y en especial las de espejo son muy corrientes en la arquitectura nazarí. Su precedente pueden ser las bóvedas con nervaduras de la arquitectura califal, algunos de cuyos plementos adoptan esta forma (Torres Balbás, 1943: 265-266).

En esta torre nos encontramos ante una sólida construcción realizada con escasos materiales: cal, zahorras y tierra y algunos ladrillos; como medios auxiliares, sólo unos pocos costeros de encofrado para forjar los cajones de tapial y un andamio ligero para hacer el acabado exterior de los muros, pues con toda seguridad el grueso de la obra se realizaría desde el interior aprovechando lo ya construido. Las bóvedas interiores se ejecutarían como ya hemos descrito, sin apenas medios auxiliares. Su fecha de construcción resulta muy difícil de precisar, dada la falta de documentos y lo impreciso de los paralelos arquitectónicos, al no existir decoración ni epigrafía. Por su buena ejecución nos inclinamos a pensar que pueda ser obra de siglo XIV, pero sin poder aportar argumentos definitivos.

\section{BÓVEDAS DE ENJARJES}

Un ejemplo claro de construcción de bóvedas sin cimbra lo constituyen las llamadas bóvedas de enjarjes o por aproximación de hiladas. Estas estructuras están formadas por piezas, ya sean ladrillos o piedras de forma prismática, que se disponen en hiladas con vuelos sucesivos a ambos lados del espacio a cubrir, hasta que entran en contacto en el centro. Aunque se las llama también falsas bóvedas, pues es cierto que durante el proceso constructivo funcionan como ménsulas y no como bóvedas, cuando la bóveda está cerrada y forma ya una masa homogénea, no cabe duda de que su comportamiento final es el de una bóveda. Este tipo de construcción es conocido desde tiempos prehistóricos existiendo notables construcciones resueltas de este modo, como la del Tesoro 
de Atreo, en Micenas. En al-Andalus se utilizaron bóvedas enjarjadas para cubrir pequeños espacios utilizando mampuestos menudos, generalmente tomados con yeso para facilitar el proceso de construcción y evitar así tener que usar piezas a modo de grandes tizones.

Hay un conjunto de bóvedas de este tipo, hechas con mampostería de piedra, en construcciones militares del siglo X, en la Marca Media. La mejor ejecutada, sin duda, está en el paso dispuesto a través de la muralla para acceder a una poterna del castillo de Gormaz (Soria). Cubre un pasillo de aproximadamente $2 \mathrm{~m}$ de luz que se cierra superiormente con tres hiladas de sillarejos por cada lado dispuestos en vuelos sucesivos de aproximadamente igual saliente que altura (Fig. 5).

Encontramos otras dos bóvedas semejantes en dos torres de parecidas características ubicadas en las serranías del Sistema Ibérico (Almagro, 1976). Una es la torre del Andador de Albarracín, torre atalaya luego convertida en castillo que protegía el flanco norte de la ciudad. El acceso desde la puerta hasta el interior de la torre se hace a través de un estrecho pasillo de apenas $1 \mathrm{~m}$ de anchura, con disposición en doble recodo y cubierto por una bóveda de enjarjes con tres hiladas en saliente por cada lado rematadas con una piedra plana superior. El otro ejemplo se encuentra en la llamada torre de los Casares, en Riba de Saelices (Guadalajara). La sala baja de esta construcción, de 1,30 m de anchura, está cubierta con una bóveda de 7 enjarjes (Fig. 6). También el paso que conduce desde la puerta al espacio anteriormente descrito se cubre de igual modo, aunque en este caso se conserva un enlucido de la bóveda que ha rellenado los salientes dándole al cubrimiento apariencia de un diedro.

Bóvedas de este tipo se usaron prolijamente en la arquitectura mudéjar de ladrillo para cubrir espacios estrechos, sobre todo pasillos y escaleras. A título de ejemplo podemos citar el caso de la torre de San Martín de Teruel (Almagro 1991b). El interior de esta torre, muy semejante a la del Salvador, también de esta misma población, es muy singular. Posee un cuerpo central que contiene tres salas superpuestas con bóvedas de ojivas, rodeadas por un estrecho espacio que las separa totalmente del muro exterior y en el que se aloja la escalera. Ésta apenas necesita algo más de un lado, de los cuatro que tiene este espacio, para subir de una planta a la siguiente, ocupando el resto un corredor horizontal que va dando vuelta a la sala interior. El corredor y las escaleras se cubren con bóvedas enjarjadas o de aproximación de hiladas, corridas en la zona del pasillo y escalonadas en la de la escalera (Fig. 7). Tanto el muro exterior como el que separa este espacio anular del central tienen un espesor de $50 \mathrm{~cm}$, mientras el corredor que los separa tiene $80 \mathrm{~cm}$. En estas torres se utiliza también esta solución para cubrir pequeñas ventanas y huecos de ventila- 
ción, así como para cerrar los espacios triangulares que definen los arcos cuadrales de la cubierta del cuerpo de campanas. No cabe duda de que el recurso a esta técnica venía en parte impuesto por el propio proceso de construcción, que debió de ser especialmente rápido (Almagro, 1991b:186). Al poderse construir escaleras y pasillos sin cimbra, y por tanto sin obstáculos que impidieran la circulación, se facilitaba el acarreo y subida de materiales por la misma escalera, evitando tenerlos que subir por el exterior. En estos casos, más que el evitar el uso de la madera, abundante por otro lado en esta región, primaron razones impuestas por el proceso constructivo para adoptar una determinada solución estructural.

\section{BÓvEDAS TABICADAS}

Se denomina bóveda tabicada a la hecha con ladrillos colocados «de plano» 0 «a tabla» de tal forma que una de sus caras de mayor dimensión se dispone dando frente al vacío, de modo que suele estar formada por una o varias hojas del espesor del grueso de un ladrillo. Los ladrillos de una misma hoja quedan por tanto unidos entre sí sólo por las cuatro caras menores. Para poder construir este tipo de bóveda se precisa el uso de yeso, único material de agarre capaz de «pegar» los ladrillos con tan pequeña superficie de unión. Cada ladrillo se va adhiriendo a los ya colocados uniéndolo por dos caras. Merced a la rapidez de fraguado del yeso, al poco tiempo los ladrillos recientemente colocados son capaces de aguantar que se les adhieran otros nuevos. En muchas ocasiones, y sólo con un pequeño desfase, se va colocando otra hoja similar, ésta ya adherida a la primera a bofetón por una de las caras mayores de los ladrillos. Actualmente esta segunda hoja se recibe con mortero de cemento, pero antiguamente se recibía también con yeso. En algunas ocasiones no existe segunda hoja, sino una gruesa capa de yeso tendida sobre la hoja inicial de ladrillo.

El origen de este tipo de bóvedas, de uso muy extendido en la Península, no ha sido suficientemente aclarado hasta el presente. Se cita el uso de bóvedas tabicadas en algunas iglesias góticas catalanas desde inicios del siglo $\mathrm{xV}$ (Basegoda, 1977; González, 1999:242). Estas bóvedas góticas han sido consideradas por muchos como el origen de este sistema constructivo, apuntando que serían una consecuencia de la técnica romana de usar grandes ladrillos bipedales sostenidos por cimbras ligeras, como encofrado perdido de las bóvedas (Casinello, 1969:101). Entre las bóvedas tabicadas más antiguas que conozco están las de las cúpulas interiores de la torre de Ambeles de Teruel 
(Almagro, 1981), obra defensiva del inicio del uso de la pólvora que puede fecharse a finales del siglo XV o comienzos del XVI. Sin embargo, estas bóvedas, formadas por una sola hoja de ladrillo, sólo servían de encofrado del relleno de hormigón de cal con que se trasdosaron. El uso muy extendido en Cataluña y Levante ha motivado el que suelan también llamarse «a la catalana». En el castillo de Villena existen dos bóvedas nervadas, al parecer almohades (Ferre, 2000), cuyos plementos están tabicados, aunque todo hace pensar que dichos plementos son el fruto de una restauración reciente, sin que se sepa a ciencia cierta cómo estaban construidos los originales. Desde el siglo XVI, y sobre todo en el siglo XVIII, se usó extensamente en la construcción de bóvedas de iglesias que habitualmente no tenían más función portante que sostenerse a sí mismas o a algún esporádico operario que pasara sobre ellas para el mantenimiento de las cubiertas. Éstas son autoportantes, formadas a base de cerchas de madera que apoyan sobre los elementos verticales de la estructura (muros y pilares), por lo que la bóveda no tiene en sí otro cometido que el de definir y cerrar el espacio interior.

Sin embargo, en una reciente visita al yacimiento de Siyāsa en julio de 2000 caímos en la cuenta de un detalle que hasta entonces había pasado inadvertido, tanto a su excavador, Julio Navarro, como a cuantos habíamos visitado en diversas ocasiones estas interesantes ruinas. La casa llamada n. ${ }^{\circ} 10$ posee dentro de su pórtico sur, y arrancando en el vano oriental del mismo, una escalera que permitía el acceso a la planta alta (Navarro y Jiménez, 1995:figs. 69-70). De dicha escalera sólo se conserva su arranque con los cuatro peldaños que se asientan en la parte maciza del inicio. Esta escalera continuaba luego sostenida por una bóveda para dejar más diáfano el pórtico en la zona en donde se sitúa además el acceso a la vivienda desde un adarve inmediato. Pues bien, esta bóveda era, a todas luces, una bóveda tabicada, según puede verse por la disposición de los ladrillos que constituían su intradós (Fig. 8). Como esta casa puede datarse entre finales del siglo XII y comienzos del xIII (Navarro y Jiménez, 1995:117), nos encontramos sin duda ante la más antigua bóveda tabicada hasta ahora conocida.

Resulta de sumo interés que este primer ejemplo conocido de bóveda tabicada se utilice en una de las aplicaciones más usuales, aunque hoy esté en desuso, de este tipo de estructuras, como es servir de soporte a una escalera (Casinello, 1969:121). La bóveda arrancaba de un macizo de fábrica de mampostería y yeso de unos $50 \mathrm{~cm}$ de altura que sirve de base a los tres primeros peldaños. Los ladrillos se disponen en hiladas regulares, con la dimensión mayor paralela a la línea de arranque y adhiriéndose a la pared lateral. Sólo se conservan dos ladrillos enteros de la primera hilada (falta uno y medio para 
completarla), otro casi entero de la segunda y un trozo de otro de la tercera, siempre adheridos al muro lateral en donde marcan la curvatura, con mucha pendiente, de la bóveda. La disposición de los ladrillos no es la que se emplea actualmente, pues se suelen disponer con las juntas continuas según la directriz de la bóveda, aprovechando el lado más largo de los ladrillos para adherirlos a la pared lateral (Casinello, 1969:104) En la bóveda de Siyāsa se dispusieron según el modo tradicional de una bóveda de sillares. En el muro lateral no se aprecia roza ni replanteo para facilitar la construcción. La bóveda, en todo caso, no tenía más que $1,30 \mathrm{~m}$ de luz.

\section{BÓVEDAS NERVADAS}

Pienso que las bóvedas nervadas, de arcos entrecruzados, tan características de la arquitectura andalusí, pueden considerarse también como un sistema encaminado a reducir la importancia de las cimbras y medios auxiliares. Una bóveda nervada es a la vez un sistema de jerarquización estructural y constructiva, ya que simplifica el problema de cubrir un gran espacio mediante un sistema de bóveda única, al convertirlo en múltiples espacios secundarios, con bóvedas de menor tamaño. La división se realiza mediante la colocación de arcos, que pueden estar dispuestos de muy distintos modos y que pueden cimbrarse con elementos auxiliares más ligeros. Construidos estos arcos, los espacios que quedan entre ellos pueden cerrarse con cimbras ligeras apoyadas en los mismos o incluso con bóvedas construidas sin cimbra (Casinello, 1969:98).

Desgraciadamente y hasta fecha reciente, poco se ha investigado sobre la verdadera forma y disposición constructiva de estas bóvedas, cuyo ejemplo más antiguo y señero en al-Andalus lo constituyen las que posee la mezquita aljama cordobesa en su segunda ampliación. Estas bóvedas cordobesas están realizadas con arcos de piedra, ateniéndose a los hábitos constructivos del califato cordobés, y parece que los plementos son de mampostería (Marfil, 1998:250, 252). Respecto a los nervios de la bóveda de arcos entrecruzados de la Capilla Real de la Mezquita-Catedral son igualmente de piedra recubiertos por la decoración de yeso (Ortiz, 1982:199) y su datación sigue siendo objeto de discusión.

Las bóvedas almorávides y almohades, claras continuadoras de este sistema constructivo, hacen de los arcos entrecruzados elementos más ligeros y por tanto de más fácil ejecución. Bóvedas de este tipo hubo al parecer en la Aljafería, pero sobre todo en época almorávide se construyen espléndidos ejemplos, como la que antecede al miḥrāb de la mezquita de Tremecén o alguna de las 
muchas existentes en la Qarawiyyīn de Fez. Seguramente, en la bóveda de arcos entrecruzados de la alcoba de la casa Toro-Buiza del alcázar sevillano (Fig. 9) se aprecie de una manera más clara el carácter sutil, casi de mera cimbra, que estos elementos alcanzan en la búsqueda de una mayor ligereza de las estructuras. En esta bóveda, los nervios, quizás prefabricados antes de ser puestos en posición, hacen una función similar a la que tienen las cerchas con que se ejecutan las bóvedas tabicadas de grandes luces (Casinello, 1969:108; Moya, 1947:10-13). En la arquitectura almohade este tipo de bóvedas se utiliza con mucha prolijidad, especialmente en construcciones de tipo militar para cubrir las salas interiores de torres. En la arquitectura mudéjar serán asimismo muy utilizadas en el cubrimiento de las características capillas qubba, sobre todo de carácter funerario (López Guzmán, 2000:173-177). En éstas los nervios suelen estar menos resaltados, predominando más su carácter decorativo sobre el tectónico. Sería de sumo interés acometer un análisis constructivo de estas bóvedas que pudiera aportarnos información sobre su verdadera forma estructural y especialmente sobre el proceso que se siguió en su construcción.

Como ya apuntara Torres Balbás (1943:482), estas bóvedas pueden ser consideradas como precursoras de las ojivales góticas y de todas las bóvedas nervadas occidentales que desarrollarán el concepto de línea-fuerza como sistema de jerarquización estructural que ha de permitir los logros constructivos del gótico (Fig 10). Todo esto viene a abundar en el carácter utilitario de los sistemas constructivos islámicos, basados en gran medida en la búsqueda de unos gastos reducidos de ejecución. El recurso a materiales pobres, de bajo coste, como son las fábricas de tapiería y ladrillo, y a estas técnicas constructivas encaminadas a conseguir soluciones efectivas con sistemas de ejecución a base de medios auxiliares limitados, son sin duda una característica que subyace en gran parte de la arquitectura andalusí, sobre todo a partir de la caída del califato cordobés. La necesidad de efectuar obras arquitectónicas, incluso suntuarias, en la fragmentada estructura política de al-Andalus, ya sin los recursos que pudo utilizar el califato, así como su adecuación a las posibilidades de la propia sociedad andalusí, facilitaron sin duda la propagación de estas técnicas, importadas desde Oriente pero pronto arraigadas con fuerza en la Península y trasmitidas por este cauce al mundo occidental.

\section{BIBLIOGRAFÍA}

Almagro, A. 1976, «Las torres bereberes de la Marca Media», Cuadernos de la Alhambra, 12, 279-315. 
—. 1981, «La Torre de Ambeles», Teruel, 66, Teruel, 239-265.

-. 1983a, El Palacio Omeya de Amman I. La Arquitectura, Madrid.

—. 1983b, «La puerta emiral de Calatayud», Homenaje al Prof. Martín Almagro Bosch, Madrid, 95-105.

—. 1986, «El yeso, material mudéjar», Actas de III Symposium Internacional de Mudejarismo, Teruel, 453-457.

—. 1991a, «La torre de Romilla. Una torre nazarí en la vega de Granada», Al-Qantara XII, 1, 225-250.

—. 1991b, «Arquitectura Mudéjar de Teruel», Borrás, G. M. (Coord), Teruel Mudéjar, Patrimonio de la Humanidad, Zaragoza.

Almagro, A.; Jiménez, P., y Navarro, J. 2000, El Palacio Omeya de Amman III, Investigación Arqueológica y restauración 1989-1997, Granada.

BASEGODA, B. 1946, La bóveda catalana, Barcelona.

BASEGODA, J. 1977, La cerámica popular en la arquitectura gótica, Barcelona.

Casinello, F 1969, Bóvedas y cúpulas de ladrillo. Manuales y normas del Instituto Eduardo Torroja de la construcción y del cemento. Madrid.

Creswell, K. A. C. 1940, Early Muslim Architecture, Vol. II, Early Abbasids, Umayyads of Cordova, Aghlabids, Tulunids and Samanids, AD 751-905, Oxford.

—. 1969, Early Muslim Architecture, Vol. I, Umayyads, AD 622-750, Part I \& II, Oxford.

FERRE, L. 2000, «Bóvedas nervadas en el Castillo de Villena», Actas del Tercer Congreso Nacional de Historia de la Construcción, vol. I, Sevilla, 304-307.

GoNZÁLEZ, J. L. 1999, «La bóveda tabicada. Su historia y su futuro», AA.VV. Tratado de Rehabilitación, Tomo I, Teoría e Historia de la Rehabilitación, Madrid, 237-259.

HERNÁNDEZ GIMÉNEZ, F. 1975, El Alminar de 'Abd al-Raḥmān III en la mezquita de Córdoba, Granada.

LÓPEZ GUZMÁN, R. 2000, Arquitectura Mudéjar, Madrid.

ManZano, R. 1995, «Casas y palacios en la Sevilla Almohade. Sus precedentes hispánicos», Navarro, J. (ed.), Casas y Palacios de Al-Andalus. Siglos XII y XIII, Barcelona, 315-352.

MARFIL RuIZ, P. 1998, «Trabajos de investigación arqueológica en las cúpulas de la maqșüra de la mezquita de Córdoba», «Nuevos datos para el conocimiento del lucernario de al-Hakam II en la Capilla de Villaviciosa de la Mezquita de Córdoba», Crónica de al-Andalus, Qurțuba, 3, 250-253.

Moya Blanco, L. 1947, Bóvedas tabicadas, Madrid.

Navarro Palazón, J., y Jiménez Castillo, P. 1995, «La decoración almohade en la arquitectura doméstica: la casa n..$^{\circ} 10$ de Siyasa», Navarro, J. (ed.), Casas y Palacios de Al-Andalus. Siglos XII y XIII, Barcelona, 117-137.

OrTIZ JuÁREZ, D. 1982, «La cúpula de la Capilla Real de la catedral de Córdoba. Posible obra almohade», Boletín de la Asociación Española de Orientalistas, XVIII, 197-216. 
AQ. XXII, 2001

SÁNCHEZ LEAL, J. 2000, «Bóvedas extremeñas y alentejanas de rosca sin cimbra», Actas del Tercer Congreso Nacional de Historia de la Construcción, vol. II, Sevilla, 9951003.

Torres BALBÁs, L. 1948, «Cáceres y su cerca almohade». Crónica Arqueológica de la España Musulmana, XXIII, Al-Andalus, XIII, 473-482.

—. 1943, «Origen árabe de la palabra francesa «ogive»», Crónica Arqueológica de la España Musulmana, XIII, Al-Andalus, VIII, 2.

TORROJA, E. 1960, Razón y ser de los tipos estructurales, Madrid.

URICE, S. 1987, Qasr Kharana in Transjordan, Durham NC.

\title{
RESUMEN
}

En este artículo se analizan cuestiones constructivas relativas a las bóvedas andalusíes, especialmente en lo referente a los medios auxiliares necesarios para su ejecución. Constituye éste un aspecto con claras influencias de otras áreas culturales que se transmitieron a través del mundo islámico.

\begin{abstract}
In this paper some questions related to construction aspects of the vaults in alAndalus are analysed, with special attention to the auxiliary means needed for its construction. This aspect shows clear influences from other cultural areas that were transmitted across the Islamic world.
\end{abstract}




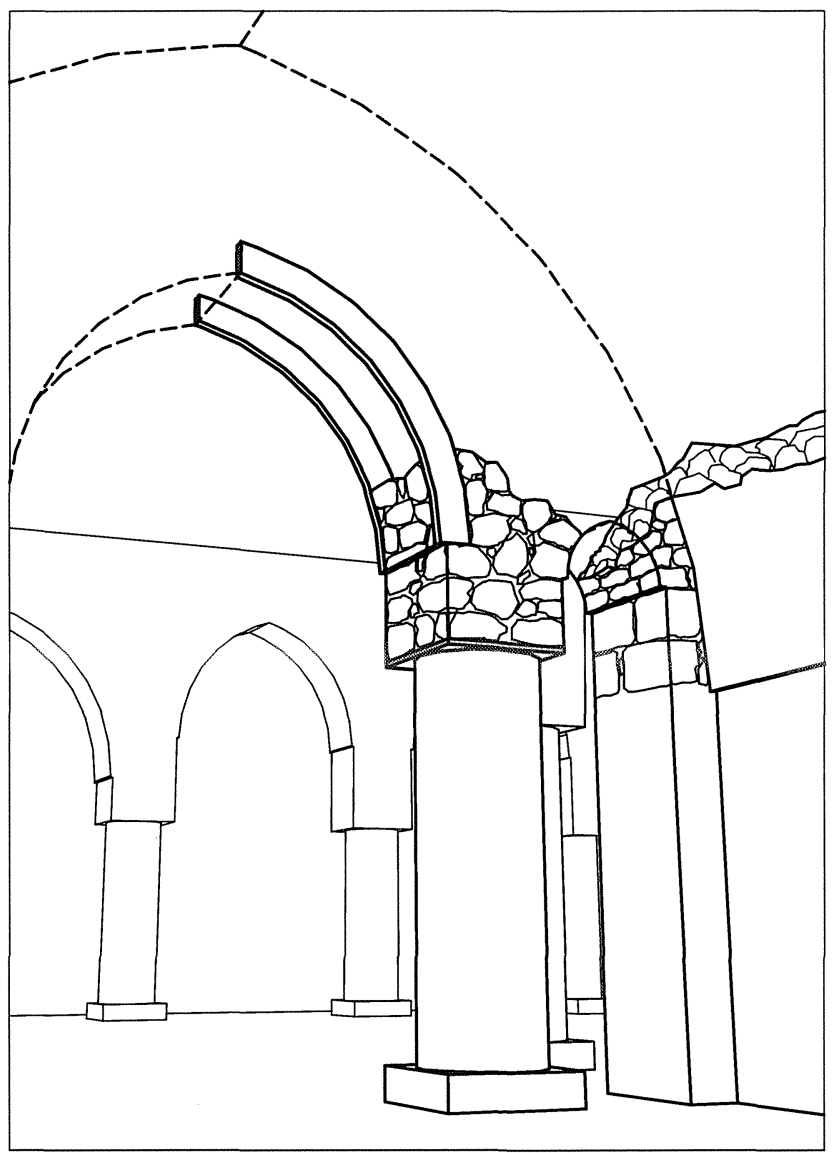

FiguRA 1. Sistema constructivo de los arcos del edificio F del Alcázar de Amman 


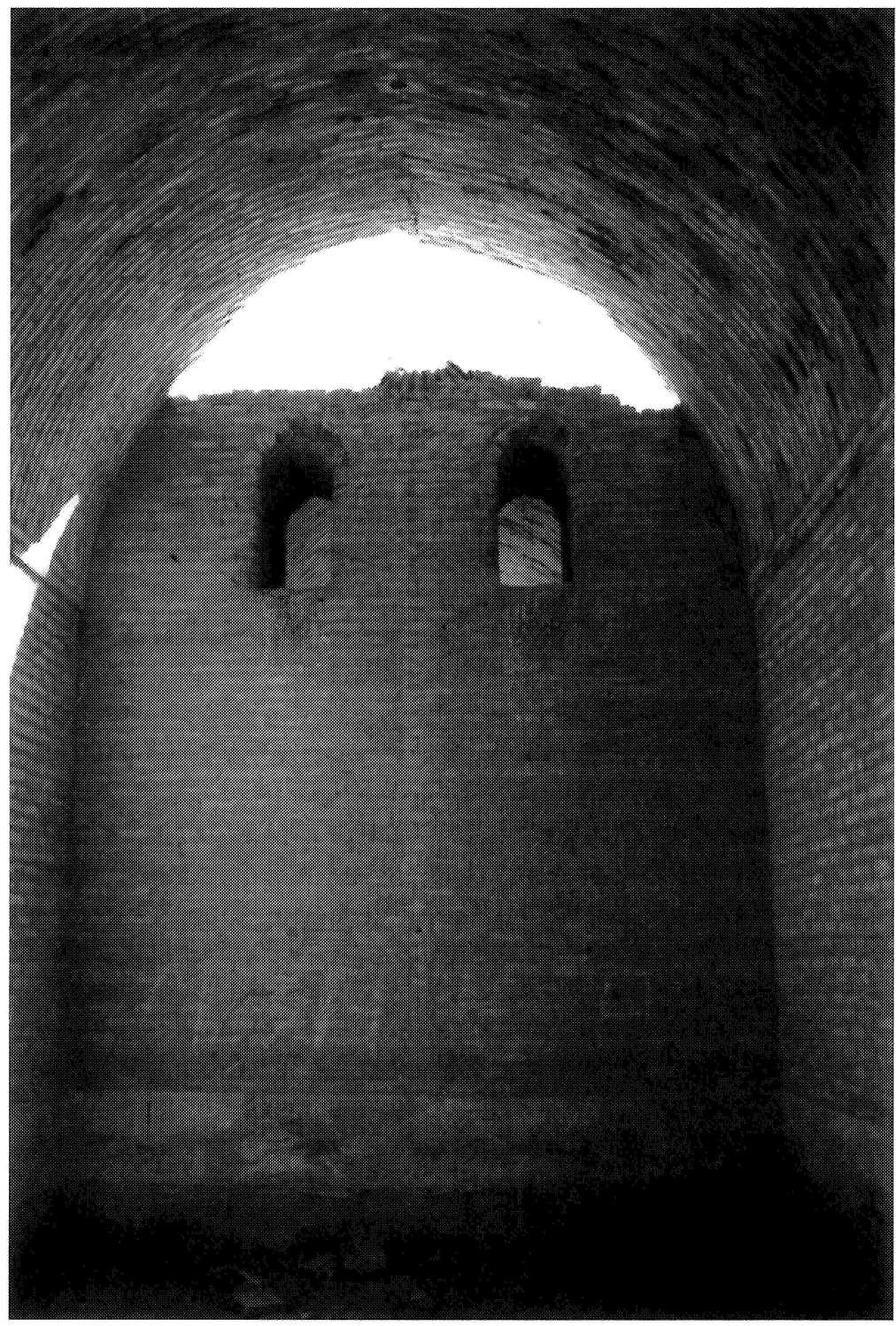

FIGURA 2. Bóveda construida sin cimbra de Qaṣr al-Ṭūba (Jordania). 


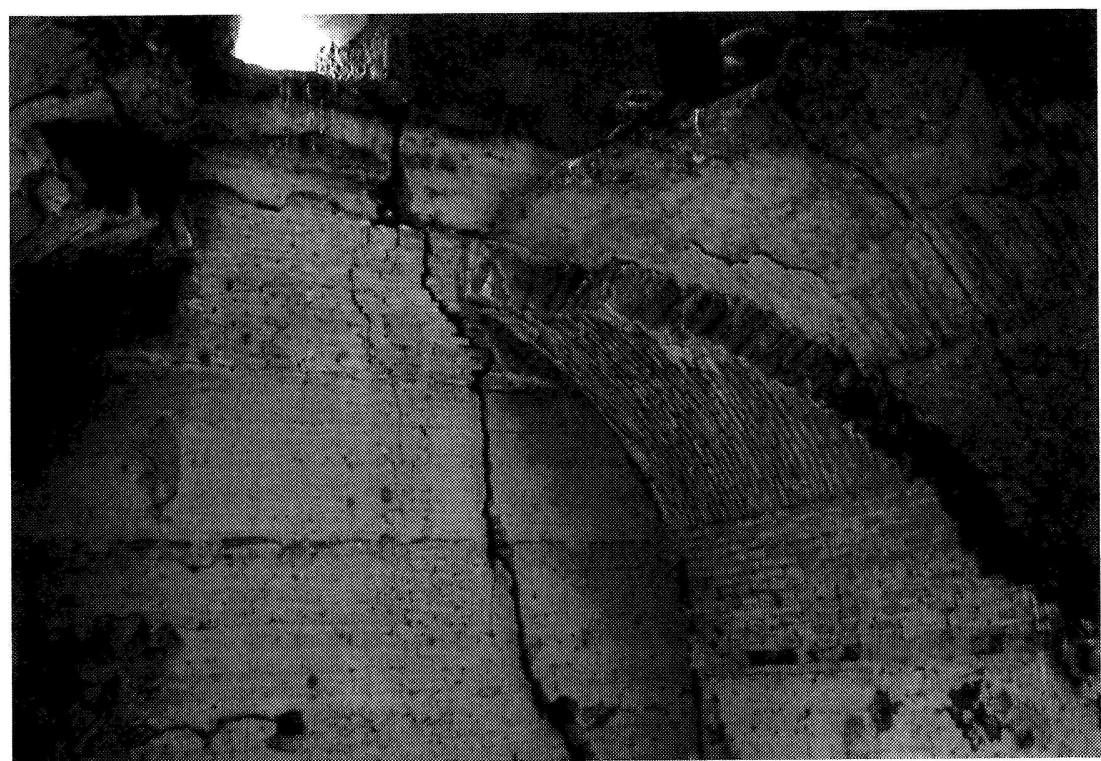

FIGURA 3. Bóveda construida sin cimbra en la torre de Romilla (Granada).
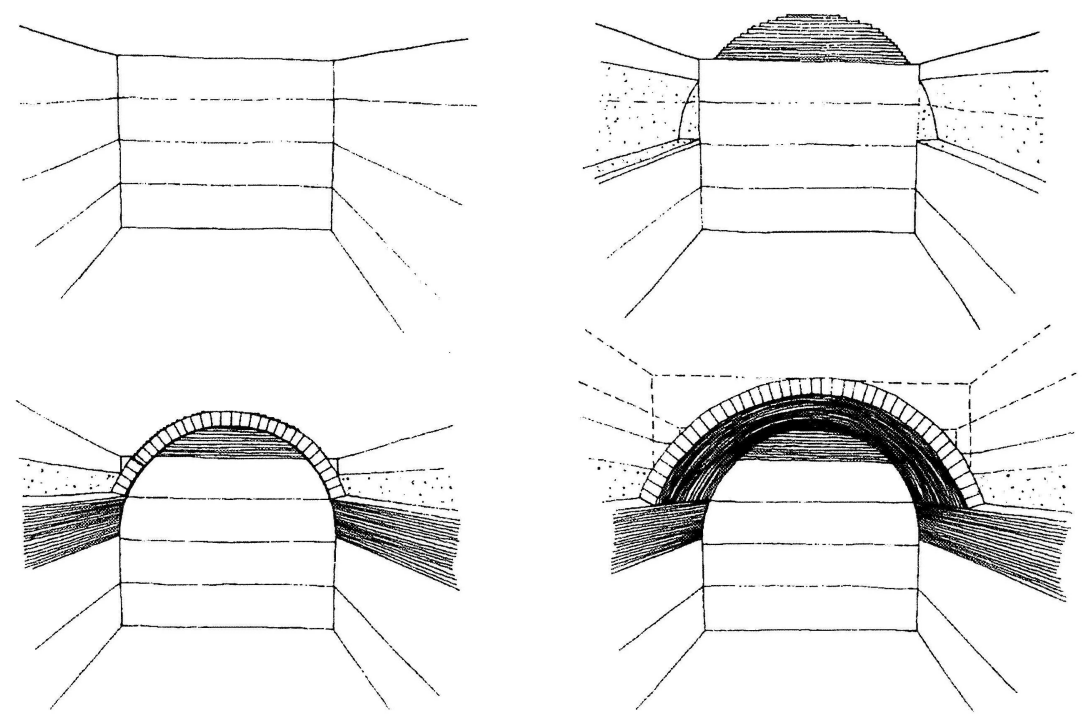

FIGURA 4. Esquema del proceso constructivo de las bóvedas de la torre de Romilla (Granada). 

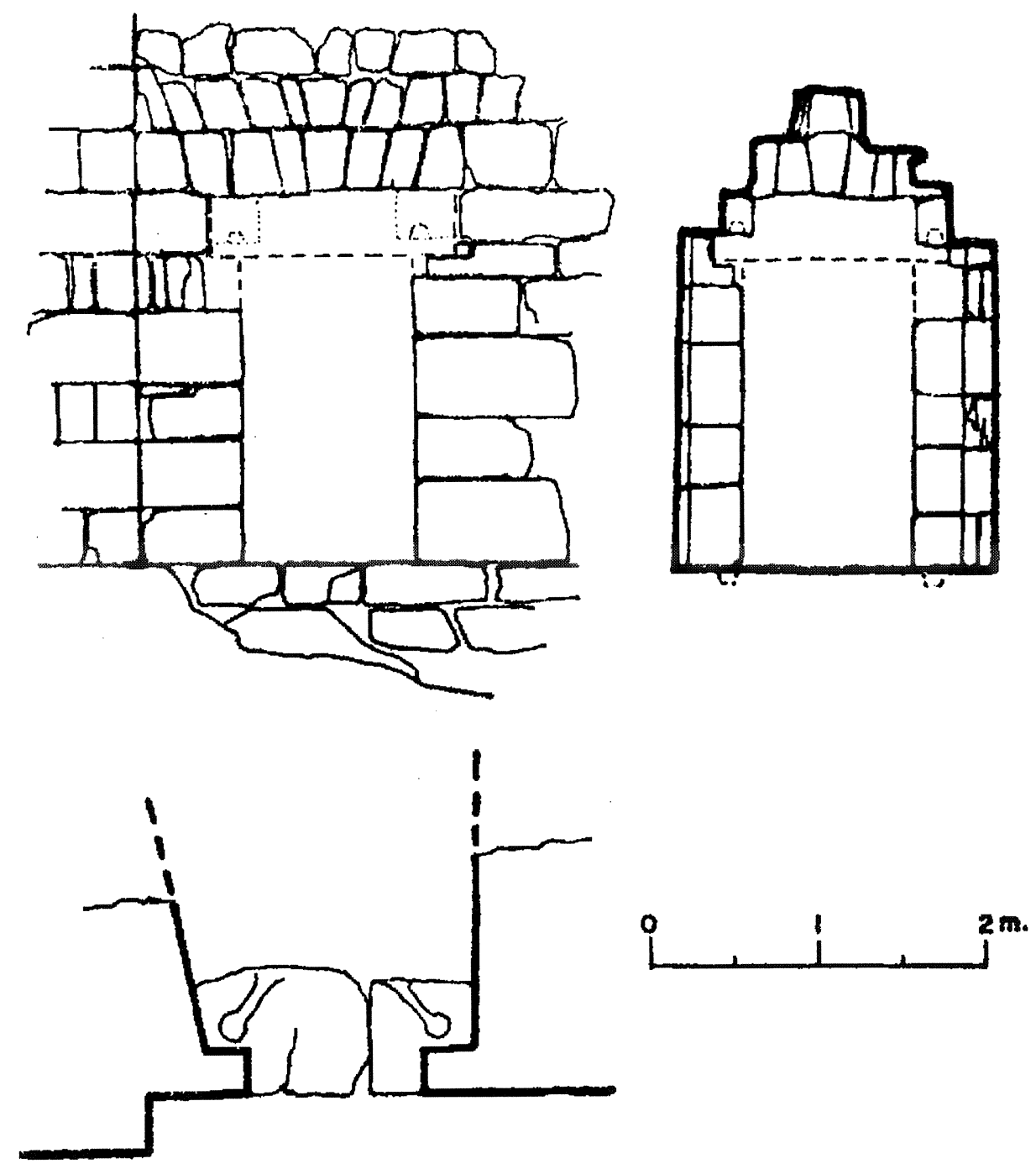

FIGURA 5. Bóveda de enjarjes de la poterna del castillo de Gormaz (Soria). 


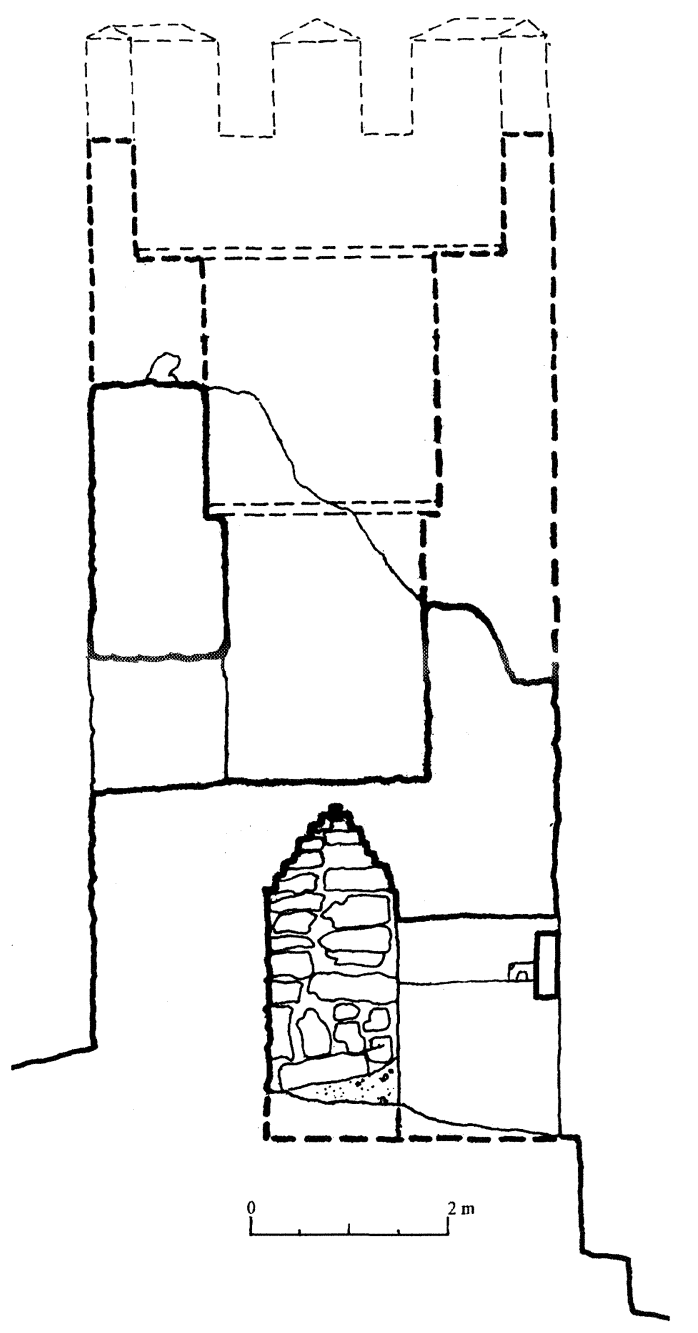

Figura 6. Bóveda enjarjada de la torre de los Casares en Riba de Saelices (Guadalajara). 

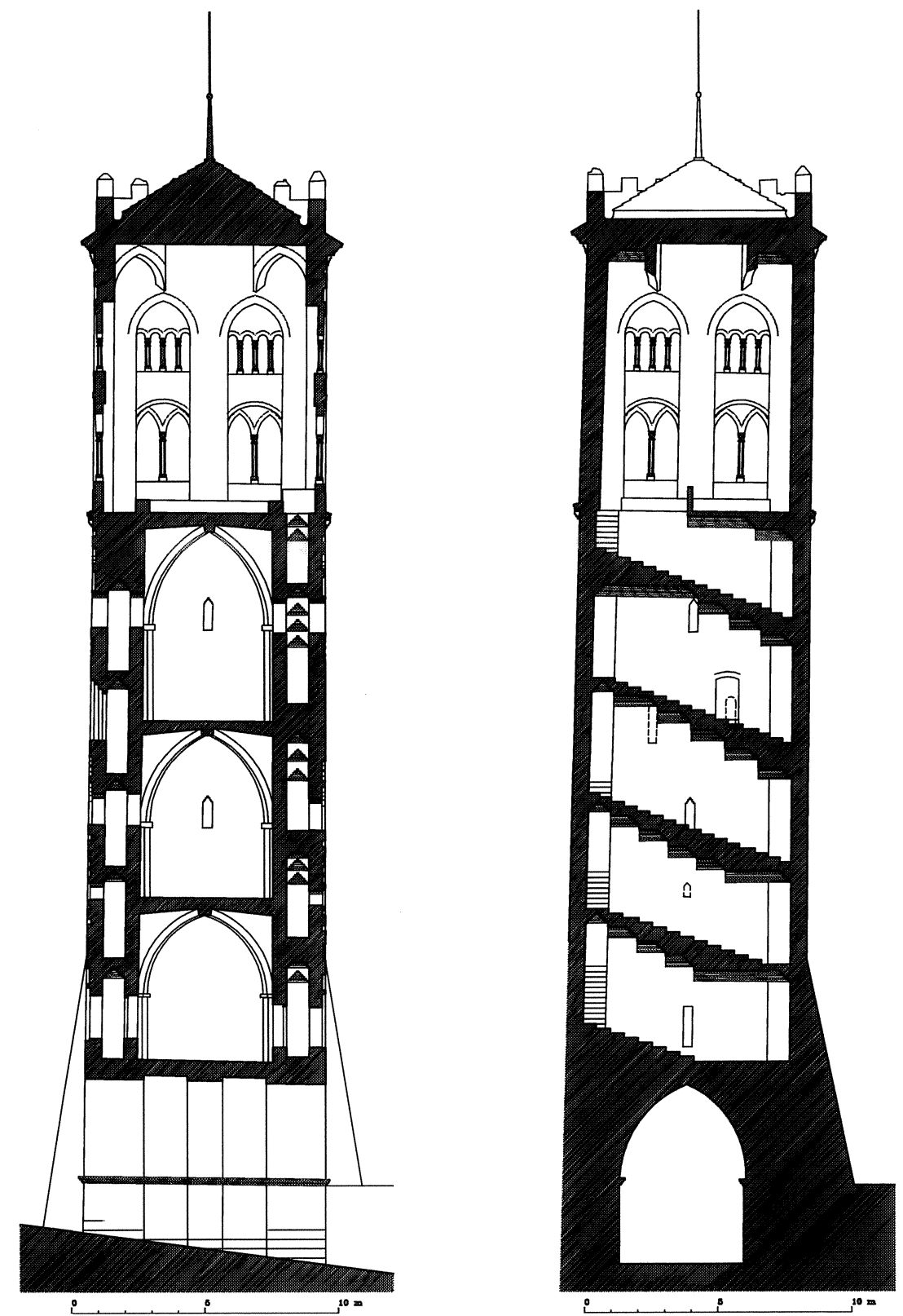

Figura 7. Secciones de la torre de San Martín de Teruel con las bóvedas de enjarjes de las escaleras. 


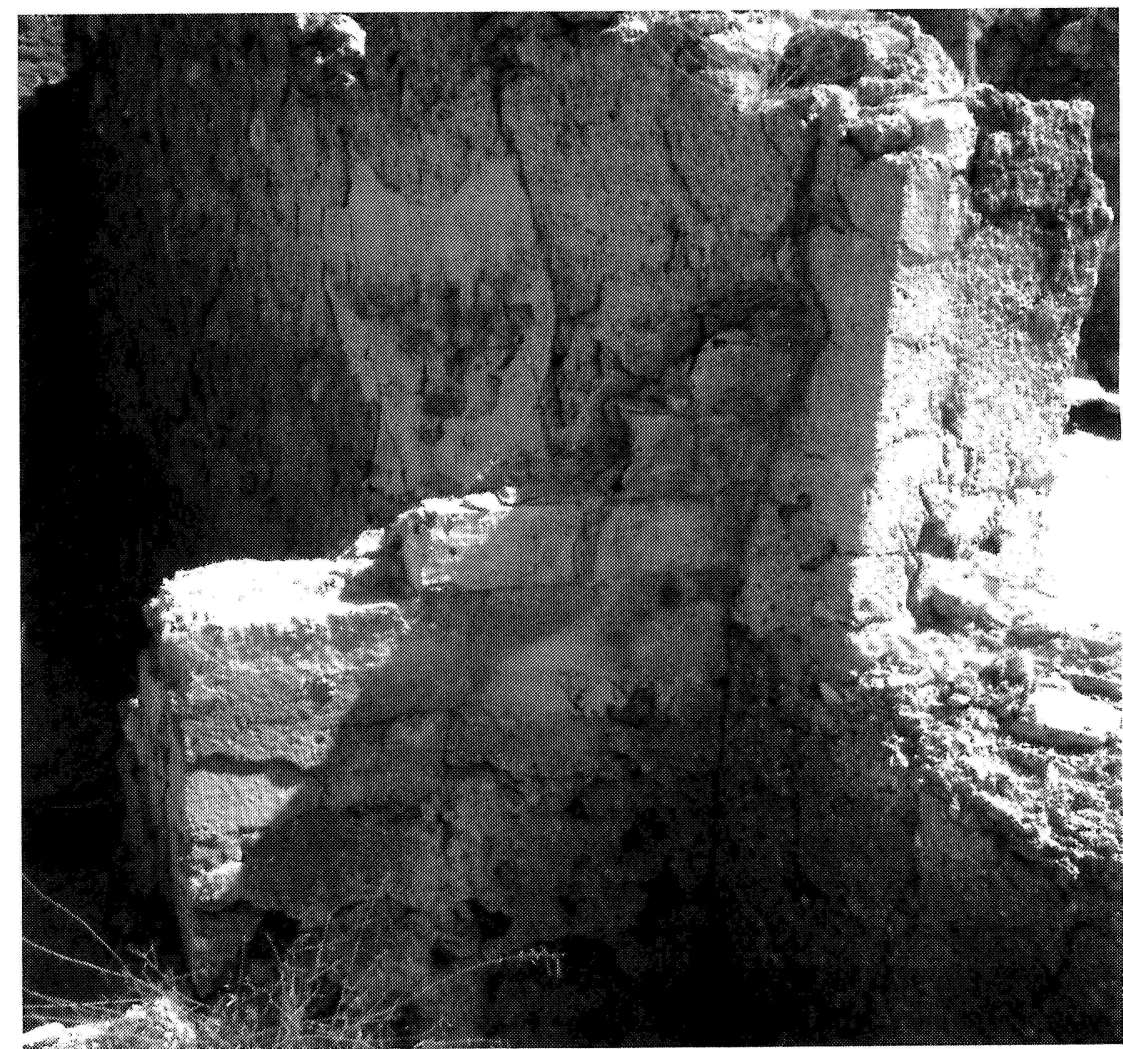

Figura 8. Arranque de la bóveda tabicada de la escalera de la casa n. ${ }^{\circ} 10$ de Siyāsa (Cieza, Murcia). 


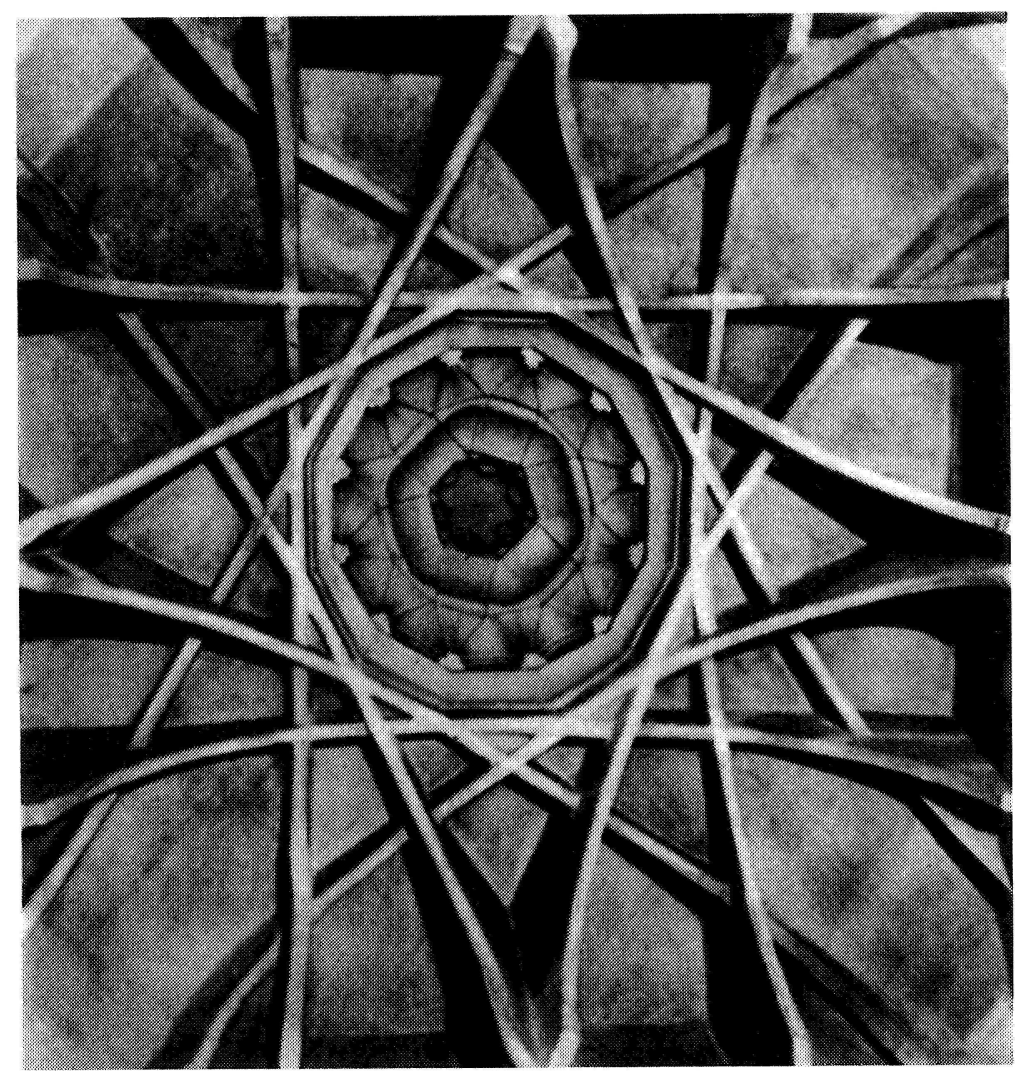

Figura 9. Bóveda de arcos entrecruzados de la casa Toro-Buiza del Alcázar de Sevilla. 


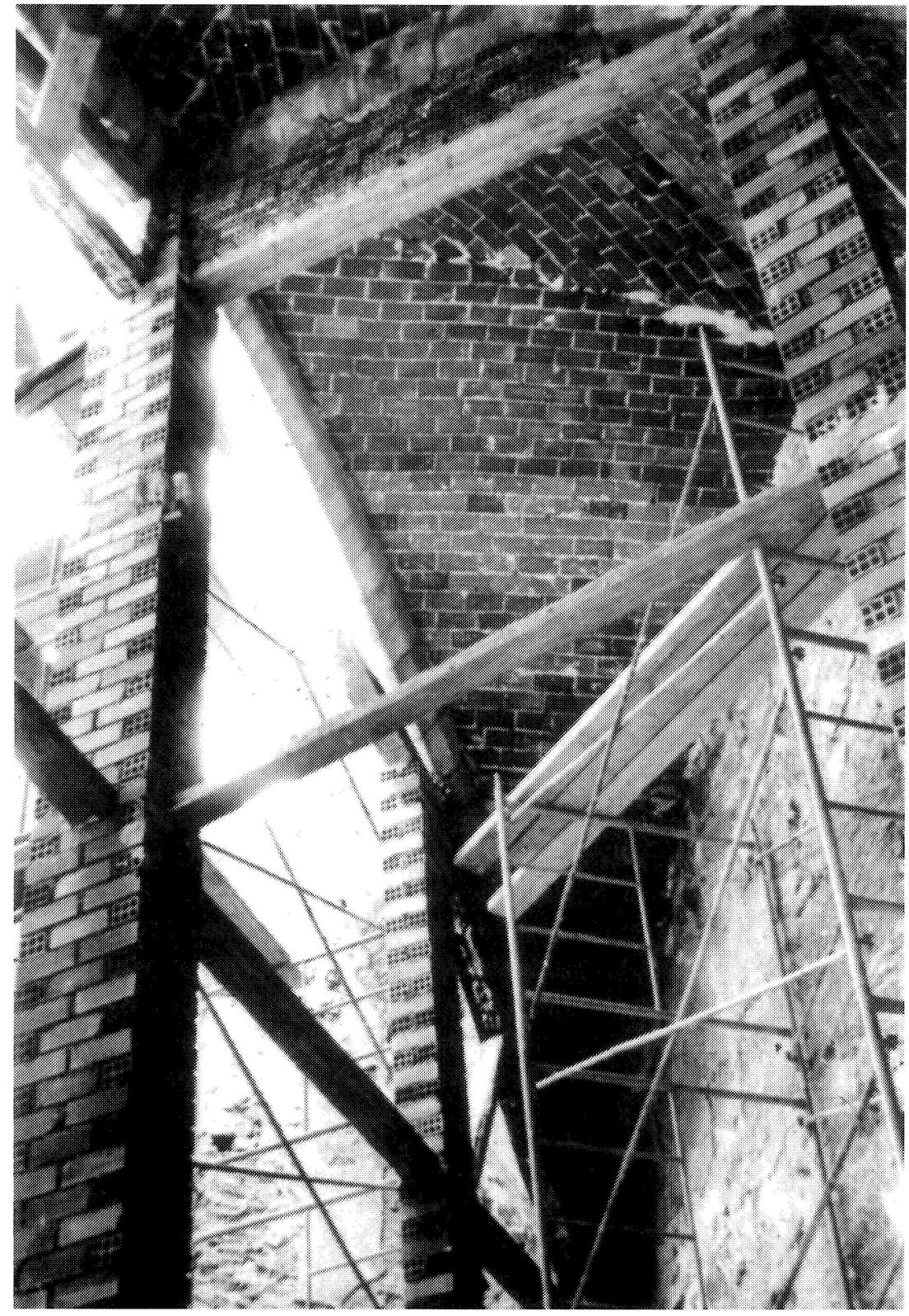

FigURA 10. Sistema constructivo de nervios y plementos tabicados en una restauración reciente. Se aprecia la simplicidad de las cimbras que soportan los nervios y la ausencia de cimbras en los plementos. 